\title{
Impaired phosphorylation and insulin-stimulated translocation to the plasma membrane of protein kinase B/Akt in adipocytes from Type II diabetic subjects
}

\author{
E. Carvalho, B. Eliasson, C. Wesslau, U.Smith \\ The Lundberg Laboratory for Diabetes Research, Department of Internal Medicine, Gothenburg University, \\ Sahlgrenska University Hospital, Gothenburg, Sweden
}

\begin{abstract}
Aims/hypothesis. To examine protein kinase B/Akt distribution and phosphorylation in response to insulin in different subcellular fractions of human fat cells from healthy subjects and subjects with Type II (noninsulin-dependent) diabetes mellitus.

Methods. We prepared subcellular fractions of plasma membranes (PM), low density microsomes and cytosol and examined gene and protein expression as well as serine and threonine phosphorylation in response to insulin.

Results. Protein kinase $\mathrm{B} / \mathrm{Akt} \mathrm{mRNA}$ as well as total protein kinase $\mathrm{B} / \mathrm{Akt}$ protein in whole-cell lysate and cytosol were similar in both groups. Insulin increased protein kinase $\mathrm{B} / \mathrm{Akt}$ translocation to the the plasma membrane about twofold $[(p<0.03)$ in non-diabetic cells but this effect was impaired in diabetic cells $(\sim 30 \% ; p>0.1)]$. In both groups, protein kinase B/Akt threonine phosphorylation considerably increased in low density microsomes and cytosol whereas serine phosphorylation was predominant in the plasma membrane. Phosphatidylinositol-dependent kinase 1 , which partially activates and phospho-
\end{abstract}

rylates protein kinase $\mathrm{B} / \mathrm{Akt}$ on the specific threonine site, was predominant in cytosol but it was also recovered in low density microsomes. Serine phosphorylation in response to insulin was considerably reduced $(50-70 \% ; p<0.05)$ in diabetic cells but threonine phosphorylation was less reduced $(\sim 20 \%)$. Wortmannin inhibited these effects of insulin supporting a role for PI3-kinase activation.

Conclusion/interpretation. Insulin stimulates a differential subcellular pattern of phosphorylation of protein kinase B/Akt. Furthermore, insulin-stimulated translocation of protein kinase B/Akt to the plasma membrane, where serine phosphorylation and full activation occurs, is impaired in Type II diabetes. Threonine phosphorylation was much less reduced. This discrepancy may be related to differential activation of phosphatidylinositol 3-kinase in the different subcellular compartments and phosphatidylinositol-dependent kinase 1 having high affinity for phosphatidylinositol phosphate 3. [Diabetologia (2000) 43: 1107-1115]

Keywords PKB/Akt, PI3-kinase, insulin action, Type II diabetes, GLUT-4.
Insulin resistance, i.e. an impaired ability of insulin to elicit its various metabolic effects including glucose

Received: 9 March 2000 and in revised form 22 May 2000

Corresponding author: Dr U. Smith, The Lundberg Laboratory for Diabetes Research, Department of Internal Medicine, Sahlgrenska University Hospital, S-413 45 Goteborg, Sweden Abbreviations: PK: Protein kinase, PM: plasma membranes, LDM: low density microsomes, PDK1: phosphatidylinositoldependent kinase 1, PI3: phosphatidylinositol-3, IRS, insulin receptor substrate, PIP, phosphatidylinositol phosphate uptake in the target tissues of fat, liver and muscle, is an important cause of Type II (non-insulin-dependent) diabetes mellitus and cardiovascular disease [1-3]. Insulin stimulates glucose uptake through the translocation of the GLUT-4 glucose transporters from intracellular site(s) to the plasma membrane [4, 5]. Insulin resistance is probably caused by defects in the insulin signal transduction pathways $[6,7]$ but reduced expression of GLUT-4 or impaired translocation or both also play a part in Type II diabetes $[8,9]$.

The insulin signalling pathways responsible for GLUT-4 translocation are still not clearly defined al- 
though much progress has been made recently [10, 11]. Activation of the insulin receptor, tyrosine kinase, leads to the phosphorylation of the key docking proteins, insulin receptor substrate 1 and 2 (IRS-1 and 2), for proteins containing Src homology 2 (SH2) like the p85 regulatory subunit of phosphatidylinositol-3 (PI3)-kinase. Activation of PI3-kinase is a key step for initiating several of insulin's metabolic effects, including glucose uptake and GLUT-4 translocation, as evidenced by the inhibitory effects of introducing a dominant negative p85 regulatory subunit as well as by the relatively specific PI3-kinase inhibitor, wortmannin [12,13].

Although activation of PI3-kinase is necessary to elicit the glucose transport stimulated by insulin, it is not sufficient on its own [14]. Several down-stream serine/threonine kinases have been identified as targets of PI3-kinase. These include protein kinase (PK)B/Akt [15], PKC $\zeta$ and $\mathrm{PKC} \lambda$ [16]. There is much evidence to support a role for PKB/Akt but contradictory results have also been found. Expressing constitutively active PKB $\alpha /$ Akt 1 in 3T3-L1 adipocytes was found to lead to GLUT-4 translocation to the plasma membrane [17]. Similarly, introduction of dominant-negative and kinase-dead PKB/Akt constructs in L6 cells inhibited insulin-stimulated glucose transport [18]. Furthermore, microinjection of a $\mathrm{PKB} /$ Akt substrate peptide or an antibody to $\mathrm{PKB} /$ Akt also inhibited the effect of insulin [19]. In contrast, another PKB/Akt dominant-negative mutant, where the two phosphorylation sites had been mutated, did not prevent insulin-stimulated GLUT-4 translocation although other inhibitory effects were found [20]. The reason for these inconsistent results is not clear but could relate to the cells used, the complex regulation of $\mathrm{PKB} / \mathrm{Akt}$ activity and cell-specific expression of the $\mathrm{PKB} / \mathrm{Akt}$ isoforms $[11,21]$. A role for $\mathrm{PKB} / \mathrm{Akt}$ is also supported by our recent findings with an inhibitor of $\mathrm{PKB} / \mathrm{Akt}$ kinase activity which, albeit not selective, did not inhibit PI3-kinase activation. Insulin-stimulated glucose transport and GLUT-4 translocation were, however, completely inhibited [22].

Insulin-stimulated $\mathrm{PKB} / \mathrm{Akt}$ activity and serine phosphorylation in whole-cell lysates were recently found to be reduced in fat cells from Type II diabetic subjects [23], probably due to upstream signalling defects leading to impaired PI3-kinase activation. In contrast, $\mathrm{PKB} / \mathrm{Akt}$ activation in muscle in response to an insulin infusion was found in one study [24] to be normal in Type II diabetic subjects but in another, where a high insulin concentration was added in vitro, to be impaired [25]. The reason for this discrepancy is not clear. Human fat cells, similar to rat and differentiated 3T3-L1 adipocytes, mainly express the $\mathrm{PKB} \beta /$ Akt 2 isoform and hardly any PKB $\alpha /$ Akt 1 [23] whereas muscle predominantly expresses PKB $\alpha /$ Akt 1 and PKB $\gamma /$ Akt 3 [21]. Similar to PI3-ki- nase activation, possibly, however, of most importance is not total $\mathrm{PKB} / \mathrm{Akt}$ activity in whole cells but the need for activation in the relevant subcellular compartments. It has been found that $\mathrm{PKB} \beta / \mathrm{Akt} 2$ is associated with the vesicles containing GLUT-4 [26] similar to PI3-kinase [27].

The present concept of PKB/Akt activation suggests that phosphatidylinositol phosphates (PIPs), the products of PI3-kinase, recruit PKB/Akt as well as phosphatidylinositol-dependent kinase 1 (PDK1), which phosphorylates $\mathrm{PKB} / \mathrm{Akt}$ on threonine 308 $(\mathrm{PKB} \alpha / \mathrm{Akt} 1)$ or $309(\mathrm{PKB} \beta / \mathrm{Akt} 2)$, to the plasma membrane where $\mathrm{PKB} / \mathrm{Akt}$ becomes phosphorylated. Full activation also, however, requires the phosphorylation of serine 473 (PKB $\alpha /$ Akt 1) or 474 (PKB $\beta /$ Akt 2) in the plasma membrane by the still unidentified PDK2 [11, 21].

We examined the PKB/Akt gene and protein expression as well as phosphorylation of the protein in response to insulin in different subcellular fractions from non-diabetic and Type II diabetic fat cells.

\section{Materials and methods}

Materials. Human insulin was from Novo Nordisk (Copenhagen, Denmark). Bovine serum albumin (BSA) (fraction V), collagenase, wortmannin and other fine chemicals were from Sigma (St. Louis, Mo., USA). Nonidet P-40 was purchased from USB (Cleveland, Ohio, USA). Antibodies specifically recognizing the serine 473/474 and threonine 308/309 phosphorylated regions of $\mathrm{PKB} \alpha /$ Akt 1 and $\mathrm{PKB} \beta /$ Akt 2 as well as a control antibody recognizing the same, but non-phosphorylated, region were purchased from New England Biolabs (Beverly, Mass., USA). Anti-GLUT-4 antibodies were a kind gift from Dr. S. W. Cushman (NIH, Bethesda, Md., USA). Protein A/G-Sepharose was from Santa Cruz (Santa Cruz, Calif., USA).

Subjects and source of adipose tissue. Specimens of human subcutaneous adipose tissue were obtained by needle biopsies or surgery for non-malignant disorders from the abdominal region of non-diabetic subjects $(n=16)$ and Type II diabetic subjects $(n=12)$. The cell proteins from the latter subjects were pooled into three groups. The Type II diabetic subjects had been diabetic for $10 \pm 2$ years and their mean $\mathrm{HbA}_{1 \mathrm{c}}$ value was $7.7 \pm 0.3 \%$ (reference $3.5-5.3 \%$ ). They were treated with oral agents alone $(n=6)$ or combined with insulin $(n=6)$. The biopsy specimens were obtained in the fasting state in the morning and at least $10 \mathrm{~h}$ after the subjects had taken their last medication. The biopsy specimens were placed in medium 199 at $37^{\circ} \mathrm{C}$ containing $25 \mathrm{mmol} / 1 \mathrm{HEPES}, 4 \%$ BSA with $5.5 \mathrm{mmol} / \mathrm{l}$ glucose. The tissue was immediately transported to the laboratory for further processing. Informed consent was obtained from the subjects and the study was approved by the ethics committee of the Gothenburg University.

Preparation of isolated human adipose cells. Adipose cells were essentially prepared as described previously [28]. Briefly, the tissue was cut into small fragments visibly free of connective tissue. About $0.6 \mathrm{~g}$ of tissue was incubated at $37^{\circ} \mathrm{C}$ in a shaking water bath with medium 199 containing $25 \mathrm{mmol} / \mathrm{l}$ HEPES, $4 \%$ BSA, $5.5 \mathrm{mmol} / 1$ glucose and $0.8 \mathrm{mg} / \mathrm{ml}$ collage- 
nase. After approximately $50 \mathrm{~min}$, liberated cells were filtered through a nylon mesh with a pore size of $400 \mu \mathrm{m}$ and washed four times in a new medium of the same composition but excluding collagenase and finally resuspended. Cell size and number were measured as described previously [28]. Cells were then incubated with the additions indicated in the Results in the presence of saturating adenosine concentrations (200 $\mathrm{nmol} / \mathrm{l}$ adenosine).

Cell lysate and immunoblotting. All cell incubations were carried out at $37^{\circ} \mathrm{C}$ in medium 199 buffered with $25 \mathrm{mmol} / \mathrm{l} \mathrm{HE}$ $\mathrm{PES}$ and with $200 \mathrm{nmol} / \mathrm{l}$ adenosine and $4 \% \mathrm{BSA}$. Isolated human adipocytes were distributed between plastic vials (12-15\% cell suspension) in a final incubation volume of $500 \mu \mathrm{l}$. Cells were incubated as described with or without 6.9 $\mathrm{nmol} / \mathrm{l}$ insulin and $1 \mu \mathrm{mol} / \mathrm{l}$ wortmannin for $10 \mathrm{~min}$. This latter inhibitor was always present for $5 \mathrm{~min}$ before insulin when combined with it. Cells were immediately separated by centrifugation through silicone oil and lysed in $0.4 \mathrm{ml}$ lysis buffer containing $25 \mathrm{mmol} / \mathrm{l}$ TRIS- $\mathrm{HCl}$, pH 7.4, $0.5 \mathrm{mmol} / 1$ EGTA, $25 \mathrm{mmol} / \mathrm{l} \mathrm{NaCl}, 1 \%$ Nonidet P-40, $1 \mathrm{mmol} / 1 \mathrm{Na}_{3} \mathrm{VO}_{4}$, $0.1 \mathrm{mmol} / \mathrm{l}$ okadaic acid, $10 \mathrm{mmol} / \mathrm{l} \mathrm{NaF}, 0.2 \mathrm{mmol} / 1$ leupeptine, $1 \mathrm{mmol} / \mathrm{l}$ benzamidine and $0.1 \mathrm{mmol} / \mathrm{l}$ 4-(2-aminoethyl)benzenesulphonylfluoride hydrochlorine (AEBSF) and rocked for $40 \mathrm{~min}$ at $4{ }^{\circ} \mathrm{C}$. Detergent-insoluble material was sedimented by centrifugation at $12,000 \times g$ for $10 \mathrm{~min}$ at $4{ }^{\circ} \mathrm{C}$ and the supernatants collected. Whole-cell lysates were boiled for $5 \mathrm{~min}$ in Laemmli buffer containing $0.5 \mathrm{mmol} / \mathrm{l}$ TRIS-HCl, $\mathrm{pH}$ 6.8, 10\% SDS, $0.1 \%$ bromophenol blue and $55 \mathrm{mmol} / \mathrm{l} \mathrm{di}-$ thiothreitol. The samples were analysed by electrophoresis on 7.5 or $10 \%$ SDS-polyacrylamide gels, the proteins transferred from the gel to nitrocellulose sheets and blocked in $5 \%$ fatfree milk. The blots were probed with the different primary antibodies according to the manufacturer's recommendations and the proteins detected by enhanced chemiluminescence using horseradish peroxidase-labelled secondary antibodies (Amersham, Buckinghamshire, UK). The intensity of the bands was quantified by a laser densitometer Phospho Imager (Molecular Dynamics, Sunnyvale, Calif., USA) and expressed in arbitrary units. Proteins were identified by the bicinchoninic acid method [29], using a commercial kit (Pierce Chemical Co., Rockford, Ill., USA).

PKB/Akt gene expression. The RNA was extracted from the cells with guanidinium thiocyanate as described [30]. Northern blots were done on total cellular RNA $(30 \mu \mathrm{g})$ with a labelled cDNA probe against $\beta$-actin as housekeeping gene and with a PCR fragment against PKB $\beta /$ Akt 2 (bp 282-1130, Accession $\mathrm{Nr} 1495936)$ in a common sequence for PKB $\alpha /$ Akt $1, \mathrm{PKB} \beta /$ Akt 2 and PKB $\gamma /$ Akt 3. The 5' sequence CGAGAGGCCGCGACCCAACAC and 3' sequence AGGCGGCCGCACATCATCTCGTA were used as primers.

Subcellular fractionation. Subcellular fractions, enriched in cytosol, plasma membranes and intracellular microsomes, were obtained after homogenisation and differential centrifugation essentially as described previously $[31,32]$. The membranes were resuspended in TES [20 mmol/l TRIS- $\mathrm{HCl}, 1 \mathrm{mmol} / 1$ EDTA, $0.25 \mathrm{~mol} / \mathrm{l}$ Sucrose). Aliquots (30 $\mu \mathrm{g}$ of protein) were mixed with sample buffer, loaded on SDS-PAGE gels, electrophoretically transferrred onto nitrocellulose sheets and immunoblotting was done using the different anti-PKB/Akt and anti-GLUT-4 antibodies.

Statistical analysis. Statistical significance was calculated using student's $t$ test, a $p$ value of less than 0.05 was considered as statistically significant.

\section{Results}

Gene and protein expression of PKB/Akt. Expression of the $P K B / A k t$ gene was measured on RNA extracted from healthy and Type II diabetic cells. The PCR fragment used in the northern blots recognized a major $3.3 \mathrm{~kb}$ transcript, also previously reported for $P K B / A k t$ [33], and a minor $2.8 \mathrm{~kb}$ transcript. As the PCR fragment was based on common sites for all known isoforms, the smaller transcript could represent the low expression of the $P K B \alpha /$ Akt 1 gene. The 3.3 and the $2.8 \mathrm{~kb}$ transcripts were, however, both equally expressed in healthy and diabetic cells (Fig. 1).

In agreement with our previous report, $\mathrm{PKB} / \mathrm{Akt}$ protein expression was similar in whole-cell lysates (not shown and [23]) and cytosol from the two patient groups (Fig. 2). Thus, the impaired insulin-stimulated activation and phosphorylation in diabetic cells (see below) cannot be accounted for by differences in protein expression.

PKB/Akt protein in subcellular fractions [cytosol, plasma membranes (PM) and low density microsomes $(L D M)]$ and mobility shift in response to insulin. Total cellular PKB/Akt was most abundantly expressed in the cytosol as this fraction represents five to ten times the protein content of the subcellular fractions. Two bands were seen in the cytosol in both patient groups in non-stimulated cells and in cells incubated with insulin and wortmannin (Fig. 2). In the presence
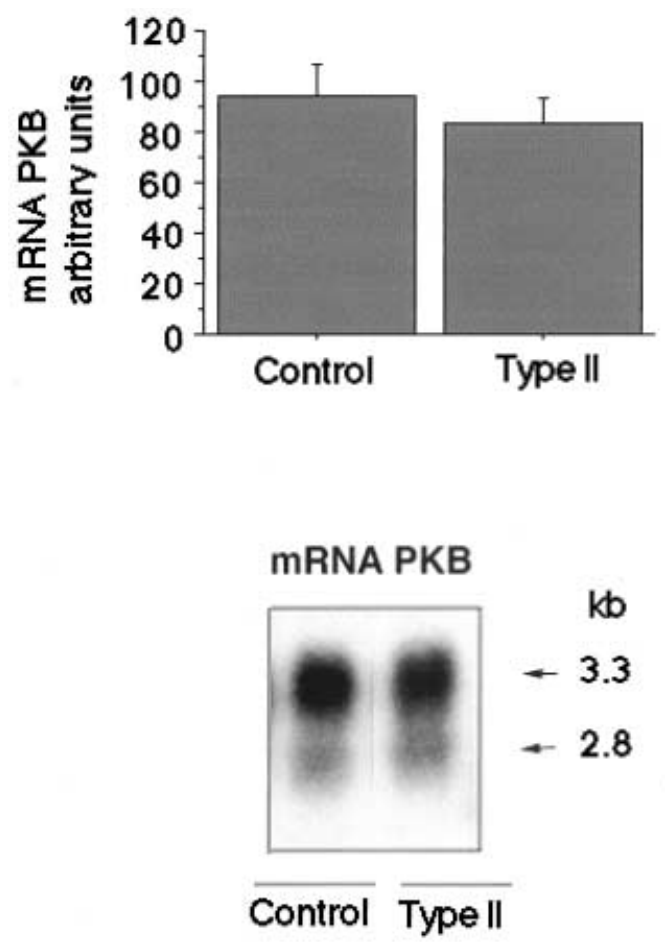

Fig. 1. PKB/Akt mRNA expression in fat cells from non-diabetic $(n=16)$ and Type II diabetic $(n=10)$ subjects 


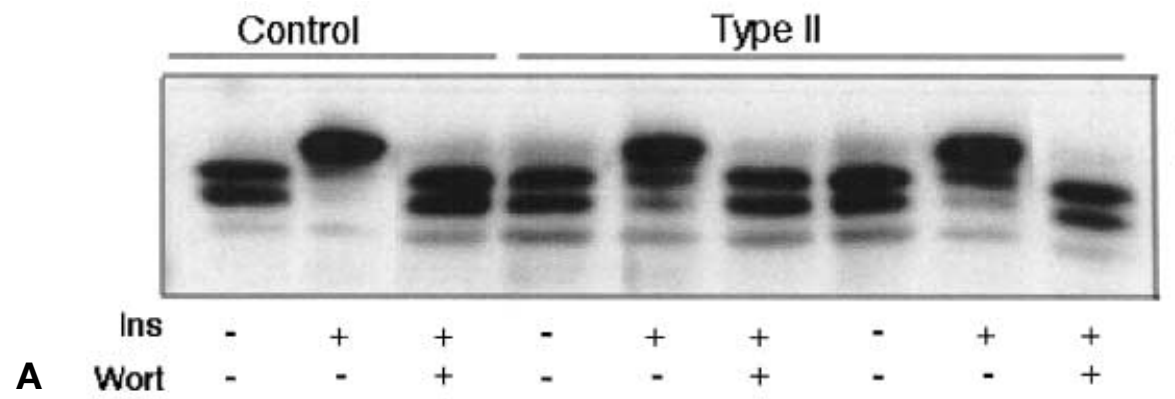

Cytosol

\section{IB: anti-PKB}

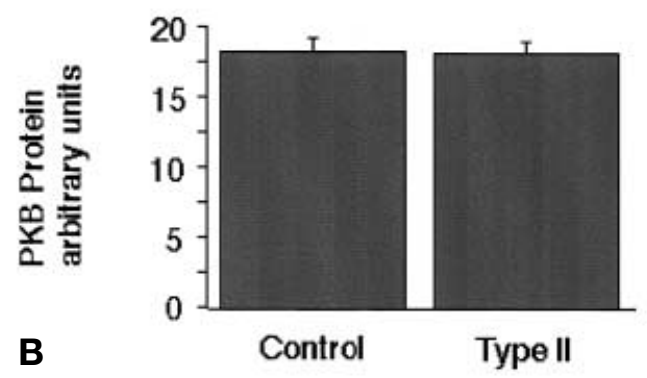

Fig. 2 A, B. PKB/Akt protein expression and mobility shift in response to insulin and wortmannin. The cells were incubated with or without wortmannin $(1 \mu \mathrm{mol} / \mathrm{l})$ for $5 \mathrm{~min}$ before 6.9 $\mathrm{nmol} / \mathrm{l}$ insulin was added for $20 \mathrm{~min}$. After homogenization, the subcellular fractions were prepared by differential ultracentrifugation. Protein $(30 \mu \mathrm{g})$ from the cytostol fraction was run on $10 \%$ SDS-PAGE, transferred and immunoblotted with anti-PKB antibody (A). The protein concentrations from basal cells (i.e. without insulin and wortmannin) were scanned with a Phospho Imager and expressed in arbitrary units (B). $n=3$ for both groups. Ins = insulin, Wort = wortmannin

of insulin, a pronounced mobility shift was, however, seen converting the two lower bands to one retarded band. This shift was less pronounced in the cytosol from the diabetic cells suggesting a lower degree of phosphorylation (Fig.2). Wortmannin inhibited the shift in mobility in response to insulin in both groups (Fig.2) showing the importance of PI3-kinase activation.

Figure $3 \mathrm{~A}$ shows $\mathrm{PKB} / \mathrm{Akt}$ protein in $\mathrm{PM}$ and LDM in response to insulin in both patient groups and Figure 3B shows the scanned data. Similar to the cytosolic fractions, at least two major bands were seen in LDM in both groups in non-stimulated cells. Insulin further retarded the upper band suggesting enhanced phosphorylation. The PKB/Akt protein concentration in LDM of non-stimulated cells was slightly $(\sim 20 \%)$ lower in the diabetic cells (Fig. 3B) but this difference was not statistically significant. Surprisingly, insulin produced a decrease in LDM PKB/ Akt concentrations in both groups (Fig. 3B) although this difference did not reach statistical significance.

In contrast to LDM, only one major $\mathrm{PKB} / \mathrm{Akt}$ band was seen in PM in non-stimulated cells
(Fig.3A). Insulin increased, however, the PKB/Akt concentration in PM from non-diabetic cells by about $100 \%$ (Fig. 3B) and also produced an additional retarded band suggesting that it was phosphorylated. The PKB/Akt translocation to PM was, as expected, inhibited by wortmannin (data not shown).

The diabetic cells also had only one major PKB/ Akt band in PM in the non-stimulated state (Fig. 3A). This band was, however, slightly retarded compared with the control cells suggesting an increased phosphorylation in the basal state but this did not involve the sites phosphorylated by insulin because they were not recognized by the specific phosphopeptide antibodies used (Figs 4A, 5A). Furthermore, the protein increase in PM in response to insulin was smaller $(\sim 30 \%)$ and not significant (Fig. 3B) and the mobility shift was also less prominent (Fig. 3A) in the diabetic cells.

Taken together, these data show a twofold increase in $\mathrm{PKB} / \mathrm{Akt}$ protein in the PM in response to insulin in control cells, suggestive of translocation from LDM or cytosol or both, but this effect was considerably reduced in diabetic cells. Furthermore, two major bands were seen in cytosol and LDM in non-stimulated cells but only one major band in PM. Insulin further increased the $\mathrm{PKB} / \mathrm{Akt}$ concentrations in PM, but not LDM, and also produced an additional, and probably phosphorylated, band in both PM and LDM.

The concentrations of GLUT- 4 were also measured in the same subcellular fractions (Fig. 3A - bottom). A clear translocation of GLUT-4 to PM and reduction in LDM in response to insulin was seen in the control cells. The GLUT-4 concentrations in the same membranes were considerably lower $(\sim 80 \%)$ in the diabetic cells and smaller reciprocal changes 


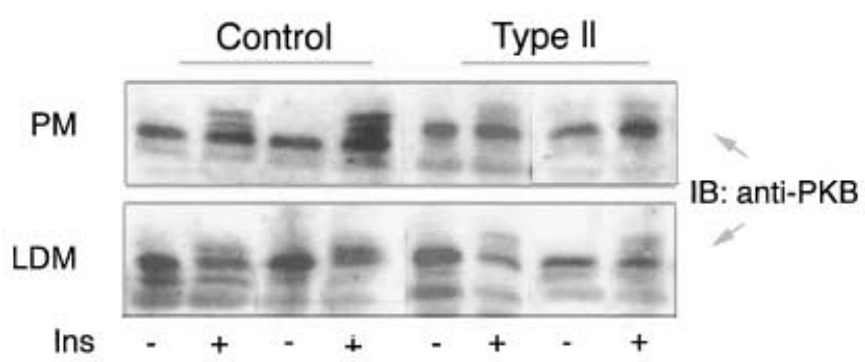

IB: anti-GLUT-4

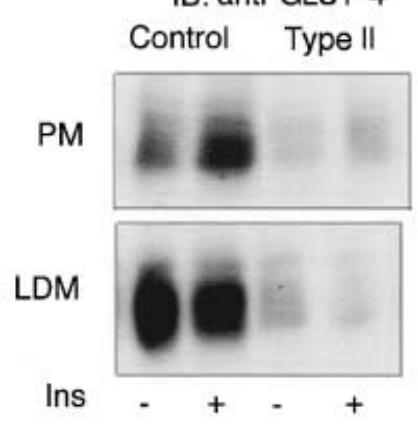

A

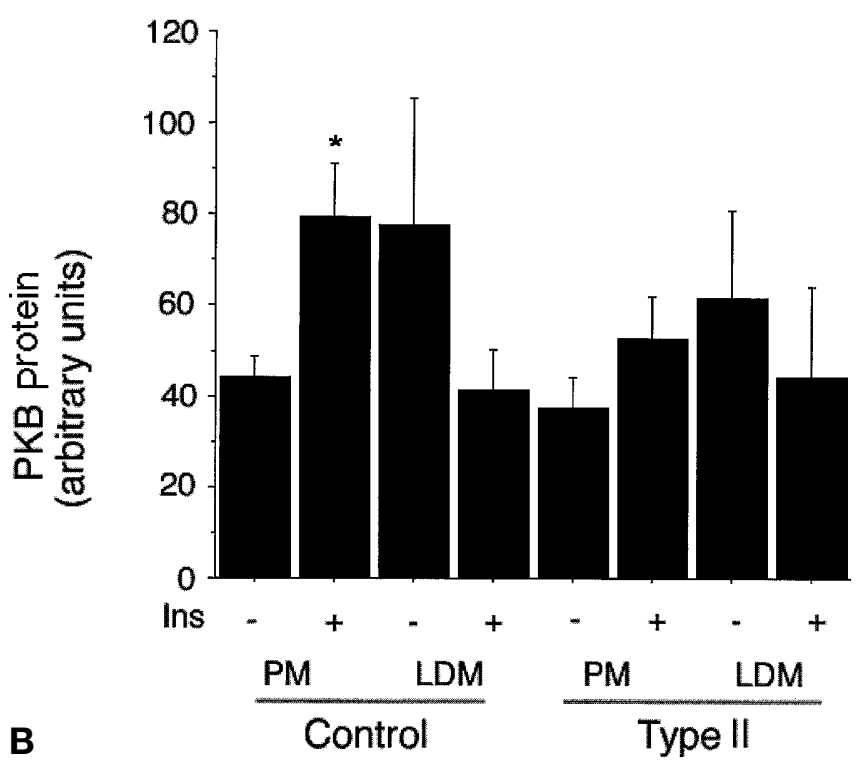

Fig. 3. A PKB/Akt protein expression in plasma membranes (PM), low density microsomes (LDM) and mobility shift in response to insulin (top). GLUT-4 protein expression and translocation from LDM to PM in response to insulin. The cells were incubated and fractionated as in Figure 2 (bottom). B Results of scanning the protein concentrations in $\mathbf{A}$ with a Phospho Imager (arbitrary units). ${ }^{*} p<0.03$ for the effect of insulin vs basal. Ins = insulin

were also seen in the subcellular compartments in these cells in response to insulin.

Serine and threonine phosphorylation in the subcellular fractions in response to insulin. Insulin increased phosphorylation of threonine and serine in all three subcellular fractions in a wortmannin-sensitive manner (Figs. 4, 5 and data not shown). A single serine-

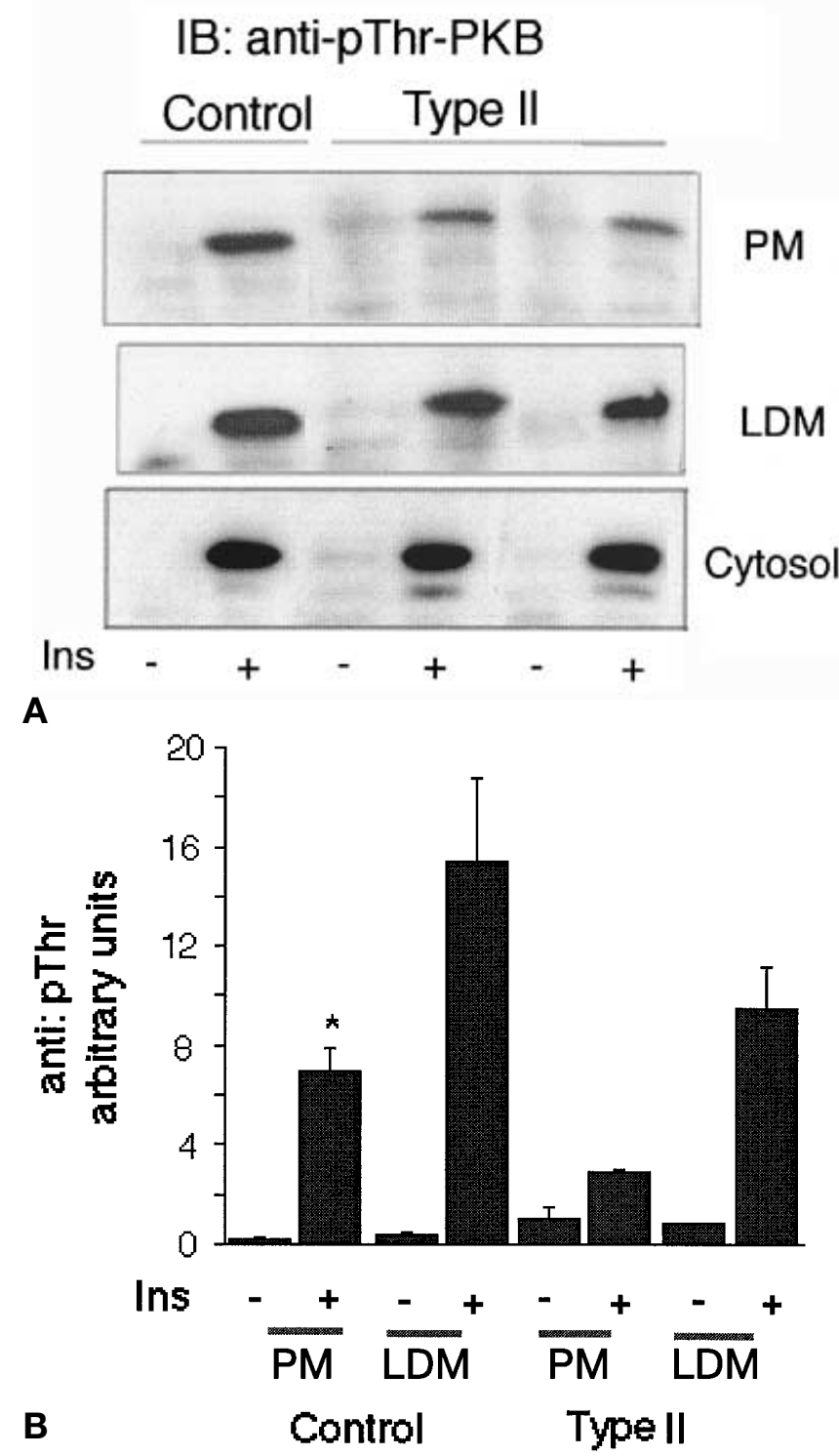

Fig. 4. A PKB/Akt threonine phosphorylation in response to insulin in PM, LDM and cytosol from the same subjects. B The relative intensity of the bands was quantified with a Phospho Imager. $* p<0.01$ for threonine phosphorylation in $\mathrm{PM}$ from control vs diabetic cells. Ins = insulin

phosphorylated band was seen in all fractions in both groups (Fig. 5A). This was also true for threonine-phosphorylated $\mathrm{PKB} / \mathrm{Akt}$ but an additional smaller phosphorylated band was seen in the diabetic cells in LDM and cytosol (Fig. 4A), probably reflecting the incomplete mobility shift in response to insulin in these cells (Figs. 2, 3).

There were, however, considerable differences in the relative phosphorylation of serine and threonine between the subcellular fractions (Figs. 4, 5) and also between the groups. The comparisons between the different subcellular fractions and the patient groups were done on immunoblots run together, loaded with the same amount of protein and using the same antibodies. In both groups, relative threo- 


\section{IB: anti - pSer-PKB}

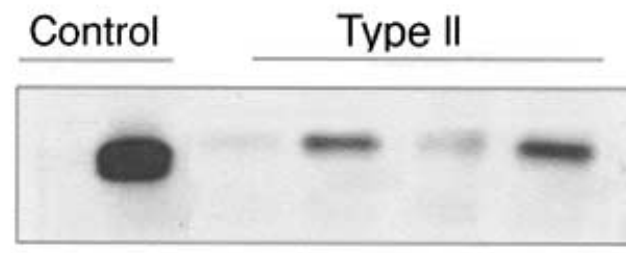

PM

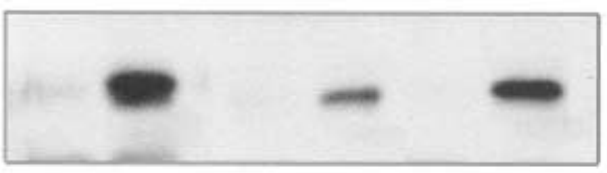

LDM
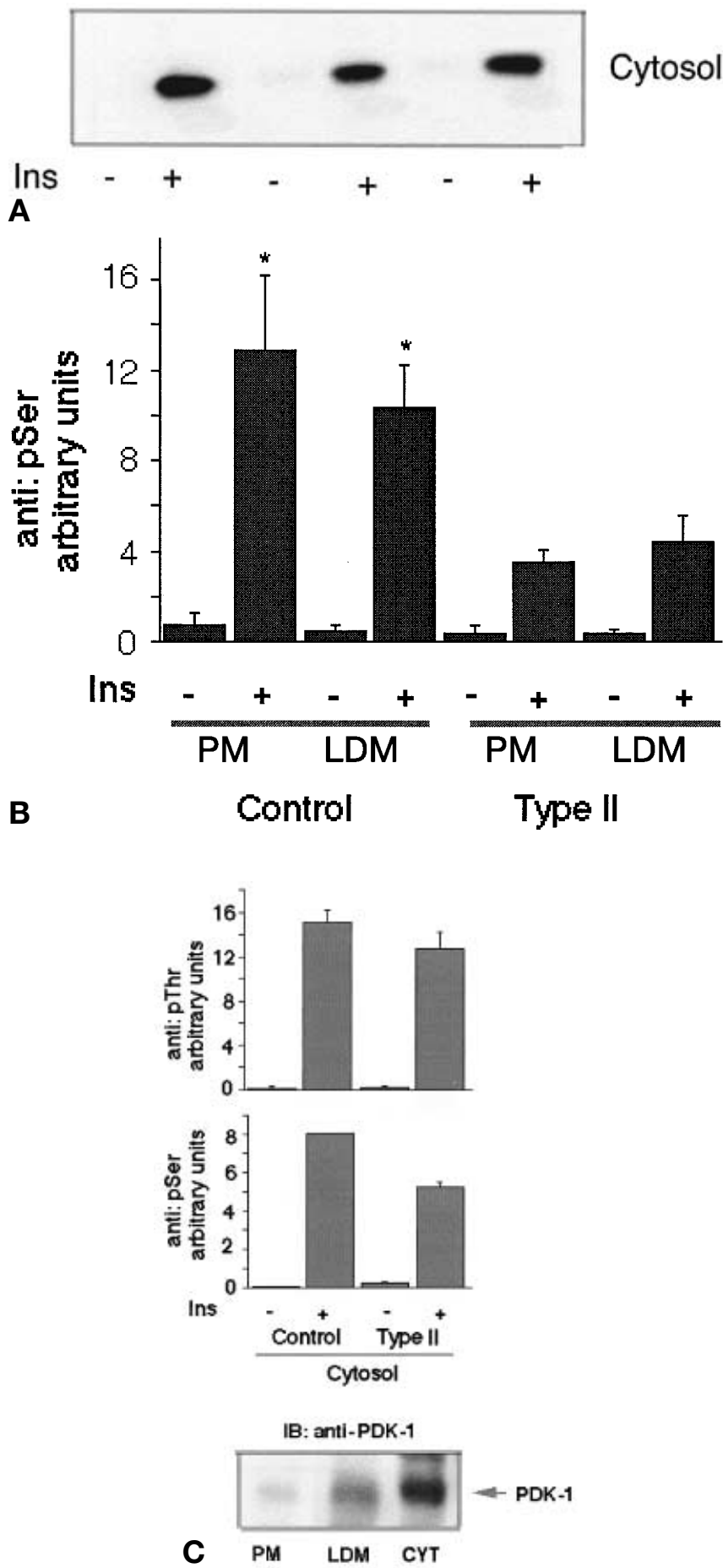

nine phosphorylation was most pronounced in the cytosol and LDM ( twofold greater than in PM) (Fig. 4). This finding was not related to differences in $\mathrm{PKB} /$ Akt protein content because, in the same blots, more protein was present in PM than LDM in the presence of insulin (Fig.3B). Phosphorylation of $\mathrm{PKB} / \mathrm{Akt}$ serine in the subcellular fractions from the same cells showed an opposite pattern; the most pronounced phosphorylation was found in PM followed by LDM and cytosol (Fig.5). Considering the differences in insulin-stimulated protein content in LDM and PM (Fig. 3B), the relative threonine phosphorylation was four to fivefold greater in LDM than in PM.

Taken together, these data show that relative threonine phosphorylation in response to insulin is predominant in LDM and cytosol whereas serine phosphorylation is predominant in PM. The difference in threonine phosphorylation could be accounted for by the presence of PDK1, the key kinase for threonine phosphorylation of $\mathrm{PKB} / \mathrm{Akt}$ in response to insulin, in LDM. Most PDK1 was recovered in the cytosol, (Fig.5C, bottom) in agreement with previous findings [34]. We also found a clear expression in LDM but much less in PM. We found, however, that PDK1 was also present in LDM from non-stimulated cells but no evidence of an insulin-induced translocation of PDK1 to LDM (data not shown).

Although serine and threonine phosphorylations were reduced in diabetic compared with non-diabetic cells, the most pronounced difference was seen in insulin-stimulated serine phosphorylation $(\sim 70 \%$ reduction in PM). This can only partly be accounted for by the reduced $\mathrm{PKB} / \mathrm{Akt}$ translocation to PM. Even considering the differences in protein translocation (Fig. 3B), PKB/Akt serine phosphorylation was still reduced about $50 \%$ in both PM and LDM and about $40 \%$ in cytosol compared with that in non-diabetic cells. The differences in threonine phosphorylation were much smaller; $10-20 \%$ in cytosol and $20-30 \%$ in PM and LDM.
Fig. 5. A PKB/Akt serine phosphorylation in response to insulin in PM, LDM and cytosol from the same subjects (also the same as in Fig. 4). B The relative intensity of the bands was quantified with a Phospho Imager. ${ }^{*} p<0.05$ for serine phosphorylation in PM and LDM, respectively, comparing control and diabetic cells. C PKB/Akt serine and threonine phosphorylation of the cytosol from control and diabetic cells (top). PDK1 expression in PM, LDM and cytosol from the same subjects. The cells were incubated and fractionated as in Fig. 2 (bottom). CYT = cytosol, Ins = insulin 


\section{Discussion}

The salient findings of this study are, firstly, differential insulin-stimulated phosphorylation patterns of $\mathrm{PKB} / \mathrm{Akt}$ in LDM and cytosol compared with PM where threonine phosphorylation was predominant in the former and serine phosphorylation in the latter. Secondly, PDK1, the key kinase for threonine phosphorylation of $\mathrm{PKB} / \mathrm{Akt}$ [21], was recovered in LDM and cytosol in basal and insulin-stimulated cells. Thirdly, evidence was obtained of an insulin-stimulated translocation (and enhanced serine phosphorylation) of $\mathrm{PKB} / \mathrm{Akt}$ to the PM. Fourthly, there was a reduced insulin-stimulated translocation of $\mathrm{PKB} / \mathrm{Akt}$ to $\mathrm{PM}$ in diabetic cells associated with an about $70 \%$ reduction in serine phosphorylation. The reduced insulin-stimulated $\mathrm{PKB} / \mathrm{Akt}$ translocation to PM cannot, however, alone account for the pronounced reduction in serine phosphorylation. Even when the differences in protein content are considered the diabetic cells still have an about $50 \%$ reduction in serine phosphorylation.

We have previously found that $\mathrm{PKB} / \mathrm{Akt}$ activity and protein serine phosphorylation in whole-cell lysates in response to insulin are reduced about $50 \%$ in diabetic cells [23]. Furthermore, similar to recent reports in rat fat cells and differentiated 3T3-L1 cells $[19,21], \mathrm{PKB} \beta / \mathrm{Akt} 2$ is highly expressed but $\mathrm{PKB} \alpha /$ Akt 1 is almost absent in human fat cells [23]. We have preliminary evidence that $\mathrm{PKB} \gamma / \mathrm{Akt} 3$ is also expressed in human fat cells but its abundance and role are under current investigation.

Although PKB/Akt was expressed as a single band in PM, similar to recent results in differentiated 3T3L1 adipocytes [19], at least two bands were found in cytosol and LDM; the subcellular fractions where insulin-stimulated threonine phosphorylation was predominant. The reason for this discrepancy is not clear but could relate to the constitutive phosphorylation of $\mathrm{PKB} \beta / \mathrm{Akt} 2$. A recent study suggests that constitutive phosphorylation of Thr 450 and, possibly, Ser 124 [35] primes PKB $\alpha / A k t 1$ for activation by growth factors when expressed in NIH 3 T3 cells [35]. Thus, constitutive phosphorylation of one or both of these sites (Thr 451 and Ser 125 in PKB $\beta /$ Akt 2) could account for the different mobility patterns in these subcellular fractions. If constitutive phosphorylation is important for subsequent activation by insulin and growth factors, our data suggest that this is particularly important for PDK1 and the phosphorylation of $\mathrm{Thr}$ 309 of $\mathrm{PKB} \beta / \mathrm{Akt} 2$. The single serine-phosphorylated and threonine-phosphorylated PKB/Akt band seen in PM also migrated as the most retarded (shifted) band suggesting that only the basally phosphorylated band became phosphorylated on the activation sites (Ser 474 and Thr 309). Similar findings were recently reported in differentiated 3T3-L1 cells [19].
Note, a PKB $\alpha /$ Akt 1 mutant of Thr 308 fails to become active even following forced membrane translocation [36].

The single $\mathrm{PKB} / \mathrm{Akt}$ band in $\mathrm{PM}$ was further retarded in non-stimulated diabetic cells suggesting an increased constitutive phosphorylation. The specific phosphopeptide antibodies to the Thr 309 and Ser 474 sites did not provide any evidence that these sites were phosphorylated in the diabetic cells in the absence of insulin. Furthermore, basal PKB/Akt activity is not increased in diabetic cells [23] providing additional evidence that the activating sites were not phosphorylated in the absence of insulin.

The current concept of $\mathrm{PKB} / \mathrm{Akt}$ activation is that of a three-step model [11, 21, 36, 37]: (1) a PH-domain-dependent step where constitutive phosphorylation of thr 450/451 and possibly ser 124/125 (PKB $\alpha / A k t ~ 1$ and $\mathrm{PKB} \beta / \mathrm{Akt} 2$, respectively) makes it responsive to subsequent activation, (2) a hormone-stimulated and PI3-kinase dependent membrane-translocation step and (3) a hormone-stimulated and PI3-kinase-dependent phosphorylation of thr 308/309 and ser 473/474.

Out data from insulin-responsive human fat cells with a large intracellular pool of vesicles containing GLUT-4 show, however, that threonine phosphorylation in LDM was increased about fourfold relative to PM. This suggests that phosphorylation by PDK1 takes place in the LDM that enclose the GLUT-4 vesicles. We also identified PDK1 in LDM, albeit at a much lower concentration than in the cytosol. Whether activation of $\mathrm{PKB} / \mathrm{Akt}$ also takes place in the cytosol, which seems less likely, or if the activated protein (re)cycles from LDM to PM and cytosol is not unclear.

There was no evidence of a further increase of threonine phosphorylation of $\mathrm{PKB} / \mathrm{Akt}$ after the translocation to PM suggesting that this mainly occurs in LDM and, possibly, the cytosol. In contrast, serine phosphorylation was increased in PM relative to LDM and cytosol after its translocation. The $\mathrm{PKB} / \mathrm{Akt}$ associated with LDM showed a similar low degree of serine phosphorylation relative to threonine as the cytosol supporting that $\mathrm{PKB} / \mathrm{Akt}$ is also recycled from the cytosol to LDM.

The threonine phosphorylation was also increased about threefold in LDM and cytosol, relative to PM, in the diabetic cells. The most striking differences between control and diabetic cells were the impaired translocation and the about $70 \%$ reduction in total serine phosphorylation. These findings are consistent with the concept that $\mathrm{PKB} / \mathrm{Akt}$ becomes serine phosphorylated following its translocation to the PM [21]. Because insulin-stimulated threonine phosphorylation was much less reduced in the diabetic cells $(\sim 20 \%)$, these data provide further support for a differential phosphorylation in LDM compared with PM. 
One possible reason for the impaired translocation and serine phosphorylation of $\mathrm{PKB} / \mathrm{Akt}$ in diabetic cells is the pronounced reduction $(\sim 70 \%)$ in IRS-1 protein expression and PI3-kinase activation by insulin [38]. Because the maximum insulin-stimulated PI3-kinase activity is reduced by about $50-70 \%$ in Type II diabetic cells [38], a major reduction in the activation of PDK2 and serine phosphorylation is expected in these cells. This concept seems, however, to be incongruent with the finding that the threonine phosphorylation and consequently activation of PDK1 (also dependent on PI3-kinase), is much less reduced. One possible explanation is that PDK1 is present in LDM and that sufficient $\mathrm{PIP}_{3}$ is locally generated for its activation by insulin. We also recovered PDK1 in LDM but found no evidence of an insulin-stimulated translocation to LDM; PDK1 was present in LDM in both stimulated and non-stimulated cells. Previous studies have also shown that PDK1 has a high affinity for PIP ${ }_{3}$ and could even be constitutively active when bound to membrane [34]. Thus, it is likely that sufficient phosphatidylinositol $[3,4,5]$ and $[3,4]$ phosphates are generated by PI3-kinase in LDM in both diabetic and control cells to allow activation of PDK1 and thus threonine phosphorylation of $\mathrm{PKB} / \mathrm{Akt}$. It is now well established that insulin stimulates the translocation of both IRS-1 and IRS-2 from the cytosol to LDM [39, 40] where the associated PI3-kinase is activated. Recent experiments with insulin in rat adipocytes have shown that about $70 \%$ of PI3-kinase activity associated with IRS 1 and 2 occurs in LDM and only about $10 \%$ in PM [40]. Because diabetic cells have a normal IRS-2 expression and associated PI3-kinase activity [38] and PDK1 has a high affinity for $\mathrm{PIP}_{3}$ it is not unreasonable to expect a normal or close to normal threonine phosphorylation of $\mathrm{PKB} / \mathrm{Akt}$. The attenuated PI3-kinase activity might, however, not generate sufficient $\mathrm{PIP}_{3}$ to bind to the $\mathrm{PH}$-domain of $\mathrm{PKB} / \mathrm{Akt}$ and allow a normal translocation to PM. Our data provide direct support for the importance of differential PI3-kinase activation in different subcellular compartments.

Although our findings are consistent with such a differential activation of PI3-kinase in different subcellular compartments, we cannot exclude other possibilities for the decreased serine phosphorylation such as an increased expression of a truncated form of PKB/Akt, which does not become serine-phosphorylated, in diabetic cells similar to that reported for $\mathrm{PKB} \gamma / \mathrm{Akt} 3$ in rodent cells [21]. An alternative possibility is that PDK2 expression or insulin-stimulated activity or both is considerably reduced in diabetic cells.

Studies in insulin-stimulated $\mathrm{PKB} /$ Akt activity in skeletal muscle from Type II diabetic patients have produced differing results. One [25] found reduced $\mathrm{PKB} /$ Akt activity in human skeletal muscle after in- cubation with a high insulin concentration, consistent with our findings. Another [24], measuring PKB/Akt activity after a euglycaemic insulin infusion, found similar levels of activation in spite of a concomitant reduction in PI3-kinase activity of about $50 \%$ in Type II diabetic muscle. It is not clear whether this dicotomy represents a difference between fat cells and muscle in insulin concentration and $\mathrm{PIP}_{3}$ generation required for $\mathrm{PKB} / \mathrm{Akt}$ translocation and full activation or to other differences in experimental design. Our data suggest, however, similar to PI3-kinase activation, $\mathrm{PKB} / \mathrm{Akt}$ phosphorylation and activation varies in specific subcellular compartments. The differential phosphorylation pattern could also have functional consequences such as regulating the binding or targetting or both of specific substrates to $\mathrm{PKB} /$ Akt.

Our data show that the relative serine and threonine phosphorylation of $\mathrm{PKB} \beta / \mathrm{Akt} 2$ varies in the different subcellular fractions; threonine is predominant in LDM and cytosol whereas serine is predominant in PM. Furthermore, in Type II diabetic cells, PKB/Akt translocation to $\mathrm{PM}$ and subsequent serine phosphorylation is considerably reduced $(\sim 70 \%)$ and the threonine phosphorylation is much less impaired $(\sim 20 \%)$. As serine and threonine phosphorylation are required for full activation of PKB/Akt, these findings probably explain the reduced $\mathrm{PKB} / \mathrm{Akt}$ activation by insulin in fat cells from Type II diabetic subjects [23].

Acknowledgements. This study was supported by grants from the Swedish Medical Research Council (project B-3506), the Swedish Diabetes Association, the European Community (QLG1-CT-1999-00674) and the IngaBritt and Arne Lundberg foundation.

\section{References}

1. Reaven GM (1995) Pathophysiology of insulin resistance in human disease. Physiol Rev 75: 473-486

2. DeFronzo RA, Bonadonna RC, Ferrannini E (1992) Pathogenesis of NIDDM. A balanced overview. Diabetes Care 15: 318-368

3. Hunter SJ, Garvey WT (1998) Insulin action and insulin resistance: diseases involving defects in insulin receptors, signal transduction, and the glucose transport effector system. Am J Med 105: 331-345

4. Cushman SW, Wardzala LJ (1980) Potential mechanism of insulin action on glucose transport in the isolated rat adipose cell. Apparent translocation of intracellular transport systems to the plasma membrane. J Biol Chem 255: 4758-4762

5. Suzuki K, Kono T (1980) Evidence that insulin causes translocation of glucose transport activity to the plasma membrane from an intracellular storage site. Proc Natl Acad Sci U S A 77: 2542-2545

6. Holman GD, Kasuga M (1997) From receptor to transporter: insulin signalling to glucose transport. Diabetologia 40: 991-1003 
7. Kellerer M, Lammers R, Haring HU (1999) Insulin signal transduction: possible mechanisms for insulin resistance. Exp Clin Endocrinol Diabetes 107: 97-106

8. Garvey WT, Maianu L, Huecksteadt TP, Birnbaum MJ, Molina JM, Ciaraldi TP (1991) Pretranslational suppression of a glucose transporter protein causes insulin resistance in adipocytes from patients with non-insulin- dependent diabetes mellitus and obesity. J Clin Invest 87: 1072-1081

9. Zierath JR, Krook A, Wallberg-Henriksson H (1998) Insulin action in skeletal muscle from patients with NIDDM. Mol Cell Biochem 182: 153-160

10. White MF (1998) The IRS-signalling system: a network of docking proteins that mediate insulin action. Mol Cell Biochem 182: 3-11

11. Meier R, Hemmings BA (1999) Regulation of protein kinase B. J Recept Signal Transduct Res 19: 121-128

12. Okada T, Kawano Y, Sakakibara T, Hazeki O, Ui M (1994) Essential role of phosphatidylinositol 3-kinase in insulininduced glucose transport and antilipolysis in rat adipocytes. Studies with a selective inhibitor wortmannin. J Biol Chem 269: 3568-3573

13. Hara K, Yonezawa K, Sakaue H et al. (1994) 1-Phosphatidylinositol 3-kinase activity is required for insulin- stimulated glucose transport but not for RAS activation in CHO cells. Proc Natl Acad Sci U S A 91: 7415-7419

14. Alessi DR, Downes CP (1998) The role of PI 3-kinase in insulin action. Biochim Biophys Acta 1436: 151-164

15. Jones PF, Jakubowicz T, Pitossi FJ, Maurer F, Hemmings BA (1991) Molecular cloning and identification of a serine/threonine protein kinase of the second-messenger subfamily. Proc Natl Acad Sci U S A 88: 4171-4175

16. Standaert ML, Bandyopadhyay G, Perez L et al. (1999) Insulin activates protein kinases C-zeta and C-lambda by an autophosphorylation-dependent mechanism and stimulates their translocation to GLUT4 vesicles and other membrane fractions in rat adipocytes. J Biol Chem 274: 25308-25316

17. Kohn AD, Summers SA, Birnbaum MJ, Roth RA (1996) Expression of a constitutively active Akt Ser/Thr kinase in 3T3-L1 adipocytes stimulates glucose uptake and glucose transporter 4 translocation. J Biol Chem 271: 31372-31378

18. Wang Q, Somwar R, Bilan PJ et al. (1999) Protein kinase $\mathrm{B} /$ Akt participates in GLUT-4 translocation by insulin in L6 myoblasts. Mol Cell Biol 19: 4008-4018

19. Hill MM, Clark SF, Tucker DF, Birnbaum MJ, James DE, Macaulay SL (1999) A role for protein kinase Bbeta/Akt2 in insulin-stimulated GLUT-4 translocation in adipocytes. Mol Cell Biol 19: 7771-7781

20. Kitamura T, Ogawa W, Sakaue H et al. (1998) Requirement for activation of the serine-threonine kinase Akt (protein kinase B) in insulin stimulation of protein synthesis but not of glucose transport. Mol Cell Biol 18: 3708-3717

21. Walker KS, Deak M, Paterson A, Hudson K, Cohen P, Alessi DR (1998) Activation of protein kinase B beta and gamma isoforms by insulin in vivo and by 3-phosphoinositide-dependent protein kinase-1 in vitro: comparison with protein kinase B alpha. Biochem J 331: 299-308

22. Smith U, Carvalho E, Mosialou E, Beguinot F, Formisano P, Rondinone C (2000) PKB Inhibition Prevents the Stimulatory Effect of Insulin on Glucose Transport and Protein Translocation but Not the Antilipolytic Effect in Rat Adipocytes. Biochem Biophys Res Commun 268: 315-320

23. Rondinone CM, Carvalho E, Wesslau C, Smith UP (1999) Impaired glucose transport and protein kinase $\mathrm{B}$ activation by insulin, but not okadaic acid, in adipocytes from subjects with Type II diabetes mellitus. Diabetologia 42: 819-825

24. Kim YB, Nikoulina SE, Ciaraldi TP, Henry RR, Kahn BB (1999) Normal insulin-dependent activation of Akt/protein kinase $\mathrm{B}$, with diminished activation of phosphoinositide 3kinase, in muscle in type 2 diabetes. J Clin Invest 104: 733-741

25. Krook A, Roth RA, Jiang XJ, Zierath JR, Wallberg-Henriksson H (1998) Insulin-stimulated Akt kinase activity is reduced in skeletal muscle from NIDDM subjects. Diabetes 47: 1281-1286

26. Calera MR, Martinez C, Liu H, Jack AK, Birnbaum MJ, Pilch PF (1998) Insulin increases the association of Akt-2 with Glut4-containing vesicles. J Biol Chem 273: 7201-7204

27. Corvera S, Czech MP (1998) Direct targets of phosphoinositide 3-kinase products in membrane traffic and signal transduction. Trends Cell Biol 8: 442-446

28. Smith U, Sjostrom L, Bjornstorp P (1972) Comparison of two methods for determining human adipose cell size. J Lipid Res 13: 822-824

29. Smith PK, Krohn RI, Hermanson GT et al. (1985) Measurement of protein using bicinchoninic acid. Anal Biochem 150: 76-85

30. Chomczynski P, Sacchi N (1987) Single-step method of RNA isolation by acid guanidinium thiocyanate- phenolchloroform extraction. Anal Biochem 162: 156-159

31. Simpson IA, Yver DR, Hissin PJ et al. (1983) Insulin-stimulated translocation of glucose transporters in the isolated rat adipose cells: characterization of subcellular fractions. Biochim Biophys Acta 763: 393-407

32. Rondinone CM, Smith U (1996) Okadaic acid exerts a full insulin-like effect on glucose transport and glucose transporter 4 translocation in human adipocytes. Evidence for a phosphatidylinositol 3-kinase-independent pathway. J Biol Chem 271: 18148-18153

33. Brodbeck D, Cron P, Hemmings BA (1999) A human protein kinase Bgamma with regulatory phosphorylation sites in the activation loop and in the C-terminal hydrophobic domain. J Biol Chem 274: 9133-9136

34. Currie RA, Walker KS, Gray A et al. (1999) Role of phosphatidylinositol 3,4,5-trisphosphate in regulating the activity and localization of 3-phosphoinositide-dependent protein kinase-1. Biochem J 337: 575-583

35. Meier R, Alessi DR, Cron P, Andjelkovic M, Hemmings BA (1997) Mitogenic activation, phosphorylation, and nuclear translocation of protein kinase Bbeta. J Biol Chem 272: 30491-30497

36. Bellacosa A, Chan TO, Ahmed NN et al. (1998) Akt activation by growth factors is a multiple-step process: the role of the PH domain. Oncogene 17: 313-325

37. Sable CL, Filippa N, Filloux C, Hemmings BA, Van Obberghen E (1998) Involvement of the pleckstrin homology domain in the insulin-stimulated activation of protein kinase B. J Biol Chem 273: 29600-29606

38. Rondinone CM, Wang LM, Lonnroth P, Wesslau C, Pierce JH, Smith U (1997) Insulin receptor substrate (IRS) 1 is reduced and IRS-2 is the main docking protein for phosphatidylinositol 3-kinase in adipocytes from subjects with noninsulin-dependent diabetes mellitus. Proc Natl Acad Sci U S A 94: 4171-4175

39. Inoue G, Cheatham B, Emkey R, Kahn CR (1998) Dynamics of insulin signalling in 3T3-L1 adipocytes. J Biol Chem 273: 11548-11555

40. Anai M, Ono H, Funaki M et al. (1998) Different subcellular distribution and regulation of expression of Insulin Receptor Substrate (IRS)-3 from those of IRS-1 and IRS-2. J Biol Chem 273: 29686-29692 